American Journal of Pharmacology and Toxicology 6 (2): 46-48, 2011

ISSN 1557-4962

(C) 2011 Science Publications

\title{
Respiratory Tract-Widening Effects of Dihydroartemisinin in Wistar Albino Rats
}

\author{
${ }^{1}$ Utoh-Nedosa Uchechukwu, ${ }^{2}$ Njoku Goddy, ${ }^{3}$ S. Nedosa Kenechi, ${ }^{4}$ A. Akah Peter, \\ ${ }^{5}$ I. Ojemudia Theophilus and ${ }^{6} \mathrm{~F}$. Anowi Chinedu \\ ${ }^{1}$ Department of Pharmacology and Toxicology, \\ Faculty of Pharmaceutical Sciences, Nnamdi Azikiwe University, \\ P.M.B. 5025, Awka, Anambra State, Nigeria \\ ${ }^{2}$ Medical Instructional Technology Unit, \\ University of Jos Medical School and Teaching Hospital, \\ University of Jos, P.M.B. 2084, Jos, Plateau State, Nigeria \\ ${ }^{3}$ Evangelical Churches of West Africa Hospital, \\ Egbe, Kogi State, Nigeria \\ ${ }^{4}$ Department of Pharmacology and Toxicology, \\ University of Nigeria, Nsukka \\ ${ }^{5}$ Department of Parasitology, \\ Federal College of Veterinary and Medical Laboratory Technology, \\ Vom, Plateau State, Nigeria \\ ${ }^{6}$ Department of Pharmacognosy and traditional Medicine, \\ Faculty of Pharmaceutical Sciences, \\ Nnamdi Azikiwe University, P.M.B. 5025 Awka, Anambra State, Nigeria
}

\begin{abstract}
Problem statement: Artemisinin-based anti-malarials are currently widely used in Asia and Africa. Not much is known about the systemic effect of dihydroartemisinin. This study therefore examine the effect of dihydroartemisinin on the lungs of Wistar albino rats. Approach: Five dosages of Dihydroartemisinin (DHA) were administered by oral intubation for 5 days to 5 test and 4 control Wistar albino rats. Distilled water was administered to the control albino rats. The dosages of DHA tested were $1 \mathrm{mg} \mathrm{kg}^{-1}$ repeated after an interval of one week 2,60 and $80 \mathrm{mg} \mathrm{kg}^{-1} \mathrm{~A}$ histological examination of the tissues of the lungs showed that dihydroartemisinin treatment caused a dose dependent widening of the lumen of the bronchial tree of the lungs of the test rats but not those of the control rats. The $2 \mathrm{mg} \mathrm{kg}^{-1}$ dose of DHA was the maximal response dose. Repetition of the same $1 \mathrm{mg}$ $\mathrm{kg}^{-1}$ dihydroartemisinin dosage after an interval of one week also produced widening effects on the bronchial tree of the test rats but not on those of the control albino rats. Results: These results suggest that widening of the air tubes of the lungs and thus increasing the volume of inspired air (by the DHAtreated subject), is an important mechanism of action of dihydroartemisinin its efficacious rapid cure of malaria. Conclusion: The findings of this study suggest that dihydroartemisinin could be explore at a future drug to be use in aiding asthma patients.
\end{abstract}

Key word: Artemisinin antimalarial, world health, malaria parasite, albino rats, dihydroartemisinin, internationally widely, photomicrographs, tree-widening effects, malaria treatment, adult rats weighing

\section{INTRODUCTION}

The artemisinin ant malarial drugs have been widely acclaimed for their fast efficacious malaria parasite schizonticidal action (Utoh-Nedosa et al., 2009). For example, dihydroartemisinin produced a cure rate of $90 \%$ in 52 patients given $120 \mathrm{mg}$ of dihydroartemisinin followed by $60 \mathrm{mg}$ once daily for 7

Corresponding Author: Utoh-Nedosa Uchechukwu, Department of Pharmacology and Toxicology, Faculty of Pharmaceutical Sciences, Nnamdi Azikiwe University, P.M.B. 5025 Awka, Anambra State, Nigeria 
days (a total dose of $480 \mathrm{mg}$ ) (Soni and Gupta, 2009; Ayudhya and Mankhetkorn, 2008). Because of the rapid malaria parasite clearance of the artemisinins, the World Health Organization approved artemisinin drugs for malaria treatment in Africa (Ayudhya and Mankhetkorn, 2008) Artemisinin/Mefloquine combination had the highest clure rate of about $98 \%$ out of the following antimalarials used for malaria treatment in Thailand between 1975 and 2000: chloroquine, $15 \mathrm{mg} \mathrm{kg}^{-1}$; Mefloquine, $25 \mathrm{mg} \mathrm{kg}^{-1}$; mefloquine/sulfadoxine/pyrimethamine; quininetetracyc line and Artemisinin/Mefloquine. The direct changeover of artemisinin drugs from local native herbal medicine to targeted internationally widely used antimalarial (Soni and Gupta, 2009; Esmaeili et al., 2009; Kapoor, 2008) calls for investigation of their direct effects on vital organs of the body. This study was done to assess the effect of dihydroartemisinin on the lungs of Wistar albino rats. Information on the effect of dihydroartemisinin on the lungs is of benefit to the large number of Africans (especially Nigerians) who currently use artemisinin antimalarial drugs.

\section{MATERIALS AND METHODS}

Five dosages of Dihydroartemisinin (DHA) were administered orally to Wistar albino rats. The tested DHA dosages were, $1 \mathrm{mg} \mathrm{Kg}^{-1}$, a repeated dosage of 1 , 2, 60 and $80 \mathrm{mg} \mathrm{kg}^{-1}$.

The Dihydroartemisinin (DHA) was administered orally for 5 days to 5 test rats while distilled water was administered to 4 control rats. Adult rats weighing 75$90 \mathrm{gm}$ received the $1 \mathrm{mg}^{-1} \mathrm{Kg}$ single dosage regimen and the repeated $1 \mathrm{mg}^{-1} \mathrm{Kg}$ dosage regimen while adult rats weighing 106-140 $\mathrm{g}$ received the 2,60 and $80 \mathrm{mg} \mathrm{kg}^{-1}$ DHA dosage regimens.

The lungs of the test and control Wister albino rats were harvested $24 \mathrm{~h}$ after the administration of the lat dose of each dosage regimen.

The harvested DHA-treated and control rat lungs were fixed in $10 \%$ Buffered formalin; trimmed and dehydrated with varying increasing strengths of alcohol $(70,80,90$ and $100 \%)$. They were then cleared with xylene; impregnated in paraffin wax; micro sectioned with a Rotary Microtome Machine and processed with an automatic Shaidon Ellich Duplex Processor. Slides of micro sections of the DHA-treated and control rat lungs were prepared and stained with Coles Haematoxylin and 1\% Eosin (H and E). The slides were then photographed with a RICCOH micrographic Camera attached to a Nicon Graphic Microscope to make photomicrographs of the test and control rats.

\section{RESULTS}

A comparism of the photomicrographs of the lungs of Dihydroartemisinin treated and control albino rats showed that Dihydroartemisinin treatment caused a dose-dependent and a dose repetition-dependent widening of the bronchial tubes of the lungs (Fig. 1). Dihydroartemisinin treatment produced a widening of the size of the lumen of the bronchi (A), the bronchioles (B), the terminal bronchioles (C) and the air sacs (D) which was observable in the cross section $(\mathrm{x})$; the longitudinal section (Y) and a mixture of the cross and longitudinal section ( $\mathrm{Z}$ ) of the lungs (Fig. 1).

Figure 1-3 the air tract-widening effects of oral Dihydroartemisinin treatment seen in the upper three photomicrographs of the lungs of DHA-treated rats.

Figure 4 and 5 the photomicrographs of the lungs of control rats.

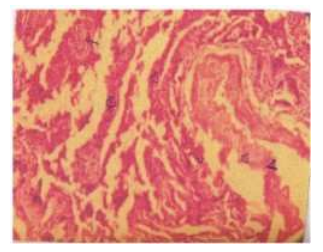

Fig. 1: The photomicrographs of the lungs dihyroartemisinin treated rats which show the bronchial tube-widening effects of dihydroartemisinin

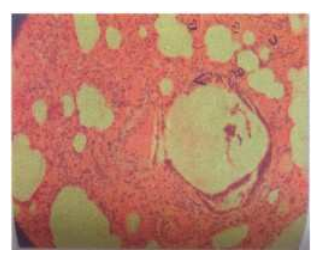

Fig. 2: The photomicrographs of the lungs dihyroartemisinin treated rats which show the bronchial tube-widening effects of dihydroartemisinin

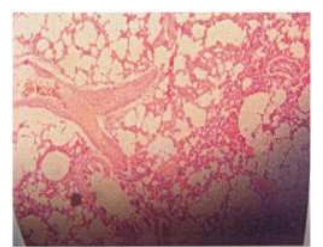

Fig. 3: The photomicrographs of the lungs dihyroartemisinin treated rats which show the bronchial tube-widening effects of dihydroartemisinin 


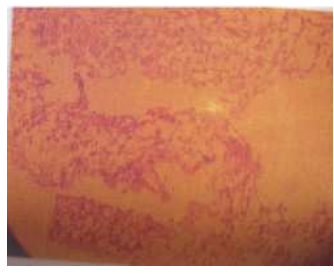

Fig. 4: The photomicrographs of the lungs control rats which show no bronchial tube-widening effects

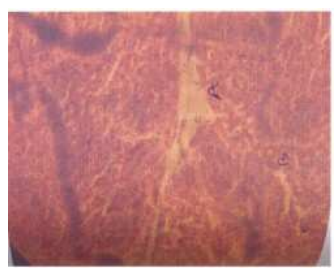

Fig. 5: The photomicrographs of the lungs control rats which show no bronchial tube-widening effects

\section{DISCUSSION}

A widening of the lumen of the bronchi, the bronchioles, the terminal bronchioles and the alveoli of the lungs directly increased the volume of air that went into the lungs the lungs of the test rats in comparism to those of the control rats. This translated into an increase in the respiratory minute volume. An increase in the respiratory minute volume translates to an increase in the volume of oxygen that got to the tissues of the test rats for oxidative phosphorylation. An increase in the volume of oxygen that reached the lung alveoli and a consequent increase in the volume of air or oxygen that got to the tissues of the body meant an increase in the efficiency of the working of the body of the DHAtreated rats. This widening action of DHA on the bronchial tree of the lungs is suggested to be as a result of the direct inhibitory action of dihydroartemisinin on the smooth muscles of the walls of the bronchial tree whose contraction constrict the bonchial tubes and therefore govern the size of their lumen.

\section{CONCLUSSION}

The bronchial tree-widening effects of dihydroartemisinin observed in this study might be of benefit in the management of disease conditions that constrict the bronchial tree or produce whizzing breathing like asthma, broncheostasis, bronchitis et cetera.

\section{REFERENCES}

Ayudhya, N.S.N. and S. Mankhetkorn, 2009. Diatrizoate, iopromide and iotrolan enhanced cytotoxicity of daunorubicin in multidrug resistant K562/adr Cells: Impaired the mitochondrial and inhibited the p-glycoprotein function. Am. J. Applied Sci., 6: 484-491. DOI: 10.3844/ajassp.2009.484.491

Esmaeili, F., G. Sepehri, G. Moshtaghi-Kashanian, M. Khaksari and N. Salari et al., 2009. The effect of acute administration of Artemisia Persia extracts on arterial blood pressure and heart rate in rats. 6 : 843-847. DOI: 10.3844/ajassp.2009.843.847 Soni, S. and S. Gupta, 2009. In vitro anti plasmodial activity of enicostemma littorale. Am. J. Infect. Dis., 5: 259-262. DOI: 10.3844/ajidsp.2009.259.262

Kapoor, R., 2008. Induced resistance in mycorrhizal tomato is correlated to concentration of jasmonic acid. OnLine J. Biol. Sci., 8: 49-56. DOI: 10.3844/ojbsci.2008.49.56

Utoh-Nedosa, A.U., P.A. Akah, T.C. Okoye and C.O. Okoli, 2009. Evaluation of the toxic effects of dihydroartemisinin on the vital organs of wistar albino rats. Am. J. Pharmacol. Toxicol., 4: 169173. DOI: $10.3844 /$ ajptsp.2009.169.173 